\title{
Dünyada ve Türkiye'de Sağlık Hizmetlerinin Dijital Pazarlanması
}

\author{
Menekşe K1liçarslan ${ }^{1 *}$ \\ ${ }^{1}$ Istanbul Aydin University, Health Management Department, İstanbul, Turkey, (ORCID: 0000-0002-0580-8645)
}

(Illk Geliş Tarihi 3 Aralık 2019 ve Kabul Tarihi 31 Aralık 2019)

(DOI: 10.31590/ejosat.654715)

\begin{abstract}
ATIF/REFERENCE: Kılıçarslan, M. (2019). Dünya da ve Türkiye De Sağlık Hizmetlerinin Dijital Pazarlanması. Avrupa Bilim ve
\end{abstract} Teknoloji Dergisi, (17), 1145-1149.

$\ddot{\mathbf{O z}}$

Dünyada gelişme gösteren teknoloji sayesinde pazarlama yaklaşımı ve yöntemleri farklı seviyelere ulaşmıştır. Geçmiş dönemdeki geleneksel yaklaşımdan, modern yaklaşımın temel yapısını oluşturan dijital pazarlama yaklaşımına geçiş sağlanmıştır. Dijital pazarlama ile birlikte sağlık alanında hizmet verilmesiyle iletişimin daha etkili sağlanmasına, çeşitli güncel konuların ele alınmasında, dijital pazarlama alanına geçiş aşamasında uyum sağlamasına ve toplumdaki fikir yöneten bireylerin katılımcı özelliğinin ön plana çıkmasını sağlamaktadır. Dijital teknolojinin oluşması aynı zaman pazarlama stratejisinin de önemli bir şekilde gelişme göstermesine olanak sağlamaktadır.

Sağlık sektörü diğer sektörlere göre insan hayatını söz konusu aldığı için ve oluşacak her bir durumda insan hayatının direkt olarak bu durumdan etkileneceğinden tüm sektörlerde var olan uygulamaların bu alana uyarlanması daha yoğun ve hassas bir çalışma gerektirmektedir. Sağlık sektöründeki dijital pazarlama süreci de tüm bu kısıtlamaların içinde insan hayatını olumsuz etkileyecek yönlendirme ve göndermelere firsat vermeden hedef kitleye erişim ve ulaşım amacıyla yöntemlerini uygulamakta ve geliştirmektedir.

Anahtar Kelimeler: Teknoloji, Dijital Pazarlama, Sağlıkta Dijital Pazarlama

\section{World in Turkey and the Deer Health Services Digital Marketing}

\begin{abstract}
Thanks to the developing technology in the world, marketing approaches and methods have reached different levels. The transition from the traditional approach in the past to the digital marketing approach, which forms the basic structure of the modern approach, has been provided. Providing services in the field of health together with digital marketing enables communication to be more effective, addressing various current issues, adapting to the stage of transition to digital marketing, and facilitating the participatory characteristics of individuals who manage ideas in the society. The creation of digital technology also enables the marketing strategy to develop significantly

Since the health sector takes human life in relation to other sectors and in every situation human life will be affected directly by this situation, adaptation of the applications in all sectors to this field requires more intensive and sensitive work. The digital marketing process in the health sector also implements and improves the methods for the purpose of reaching and reaching the target group without giving any opportunity to forwarding and referencing the human life negatively.
\end{abstract}

Key words: Technology, Digital Marketing, Digital Marketing in Health

\section{Giriş}

İçerik yönetimi

Etkili bir Arama Motoru Optimizasyonunu ilgili ve olağanüstü içerikle gerçekleştirmek mümkündür. Hastanenin tasarlayacağ içeriğe ve blog sitelerine sahip arama motorlarında en üst sıralarda var olan potansiyel ve sadık müşsteriler için, sağlık bakım hizmetlerini

* Istanbul Aydin University, Health Management Department, İstanbul, Turkey, ORCID: 0000-0002-0580-8645, meneksekilicarslan69@,gmail.com.tr 
talep eden hastalar her daim kullanılabilir hale getirilebilir. Etkili yazılıma sahip bir hastane web sitesiyle, müşterilerin ilgisini kolaylıkla sağlayabilirsiniz. (Gülmez, 2011).

\section{Pazarlama Kavramı}

Pazarlama kelimesi çok farklı şekillerde incelenmiş bir kavram olarak karşımıza çıkmaktadır. Bazı araştırmacılar pazarlamayı dağıtım veya satış konusunu incelemişken, bazı araştırmacılar ise pazarlamayı reklam kapsamında incelemiş̧ir. Bu temel tanımlama ile beraber Pazarlama kavramı bir ifade ile tüketicilerin ihtiyaçlarını karşılama anlamını taşıyan olduğunu araştırmalar da mevcuttur. Bunun yanında bu unsurun yalnızca bir olduğunu düşünen kesim de vardır. Pazarlama yalnızca satışı ifade etmemektedir. Firmaların pazarlama departmanları, mevcut veya potansiyel müşteri ihtiyaç ve isteklerine hitap eden mal ve hizmetlerin üretilmesini sağlayıp, bunların etkili biçimde müşterilere ulaşmasını ayrıca Bununla birlikte pazarlama konusu mal ve hizmetlerle alakalı reklam faaliyetlerinin yürütülmesini sağlayarak müşsteriler tarafından tercih edilerek hizmet veya ürünlerin satın alınmasını sağlamaktadırlar. Nihayetinde satış sonrasında ise satılan ürünlerin veya verilen hizmetlerin müşterileri memnun etme derecesinin araştırılması da pazarlama departmanlarınca yapılmaktadır (Bilge ve Göksu, 2010) .

\section{Dijital Pazarlama Kavramı}

80’li yıllarla birlikte dünyada internet kavramının ortaya çıkıp yaygınlaşması ile günümüze kadar gelen süreçte devamlı olarak şekil değiştirmiş ve hayatımızın her alanında kendine yer bulmuş olmasıyla bu durumdan en çok etkilenen alanlardan biri de tartışmaya yer olmayacak şekilde pazarlamadır.

Sürecin ve yeniliklerin farkında olan üreticiler tüketiciye hızlı ve doğrudan ulaşma yöntemi olarak interneti tercih etmekte ve her geçen gün daha fazla kullanmak istemektedir. Bu gelişmeler herkesin yakından takip etmeye başladığı "Dijital Pazarlama" sürecini hızlandırmış durumdadır (Yöndar Karabeyoğlu,2018) .

Küresel Dünyamızda Günümüzdeki gelişmeler ve internet sayesinde pazarlar artık neredeyse tek bir pazar haline gelmiştir. İnsanlar gerek temel gerekse özel olan neredeyse tüm ihtiyaçlarını çok hızlı ve kolay biçimde karşılayabilir hale gelmiştir. Dolayısıyla insanların istek ve arzuları çok hızlı bir biçimde değişmekte ve bir an evvel karşılanma ihtiyacı duymaktadır.

İşte tüm bu zorlu koşullar ve insanların sonsuz istekleri karşısında işletmelerin yoğun rekabet ortamlarında ayakta kalmaya çalışmaktadırlar Ticaretin giderek elektronik ortama taşınması ticaretin dijitalleşmesine neden olmaktadır (Akar ve Kayahan, 2007) .

Firma ve markalar, içinde bulunduğumuz teknoloji çağında rakipleri ile mücadele edebilmesi için geleneksel pazarlama yöntemlerinin yanında teknolojik yöntemler de tercih etmektedirler. Markaların, geleneksel pazarlama yöntemlerini günümüz teknolojisi ile birleştirmeleri, pazarlarında tüketici ile olan etkileşimleri ve ihtiyaç karşılama oranlarında dijital pazarlamayı tercih etmektedirler. Firmalar dijital pazarlama uygulamalarını akıllı telefon uygulamaları, dijital reklamlar gibi faaliyetlerle kendi bünyelerinde geliştirerek kullanıcılarla bütünleştirmesi gerekmektedir. Dijital pazarlama uygulamaları, ürün ve hizmetlerin tüketiciyle hızlı ve düşük maliyetler ile buluşma imkânı sağlamakta olup, yenliğin ve yaratıcılığın hızlı bir şekilde tüketildiği bir Pazar olarak karşımıza çıkmaktadır. Bu nedenle dijital pazarlama alanında firmaların stratejik faaliyetleri hedef olarak belirlenen Pazar kitlesinin kişilik özelliklerini, ihtiyaçlarını ve buna bağlı olarak davranış şekillerini dikkate alarak sürekli bir biçimde yenilenmek ve kreatif olmak zorundadır. Dijital pazarlama stratejileri, bütün multimedya özelliklerini kullanarak bir bütün oluşturması gerekmektedir (Yöndar Karabeyoğlu,2018) .

Sosyal medya ile dijital pazarlamanın sıkı ilişkisi, devamlı ve sürekli artan kullanıcı sayıları ile birlikte Firmalar ve markalar için artık başlı başına bir Pazar gücü anlamına gelmektedir. Gazeteye veya Televizyon Radyodan verilen reklam ilanları gibi Cep telefonlarından SMS ile haberleşilen günler çok eskide kalmasa bile o günlerle günümüz arasında çok büyük bir teknoloji farkı bulunmaktadır Bunun sebebi teknolojik gelişmelerin son 10 yıl içerisinde yaşamış olduğu gelişim patlamasıdır. İnteraktif dünya, sosyal medya ve internet; radyo ve televizyon gibi tek taraflı iletişim araçlarına kıyasla reklam dünyası için oldukça hareketli kalmaktadır. Sıra dışı bir şekilde her gün değişen ve gelişen bu platformlara, markalar pazarlama stratejilerini bu hız ve isteklere entegre etmeye çalışmaktadırlar.

İnsanların dijital alanla ve interaktif dünya ile etkileşimleri İnternet, akıllı telefonlar, bilgisayarlar, tabletler gibi araçlar üzerinden her geçen gün daha da artmaktadır. Söz konusu bu değişim kurumların da interaktif ve elektronik ortamlardan değişime cevap vermelerine neden olmaktadır (Moon Millison, 2003) .

\section{Dijital Pazarlamanın Türkiye'deki Durumu}

Günümüzde, pek çok kişi neredeyse tüm işlemlerini interaktif kitle iletişim araçları üzerinden dijital ortamda yapmaktadır. İnterneti kullanıp aynı zamanda müzik dinleyip, güncel haberleri okuyup, televizyon izleyen kişilerin sayısı oldukça fazladır Ancak bu kişilerin bilimsel araştırmalara göre herhangi bir şeye 15 dakikadan fazla odaklanamadığı bilinmektedir. Bu kısa zaman içerisinde; internet üzerindeki odaklanma işlevi oldukça hassastır. Marka ve firmalar potansiyel ve mevcut müşterilerinin dikkatini çok hızlı bir biçimde çekmek zorundadır. Günümüzde, insanlar internet kullanımının yaygınlığına ek olarak büyüyen ve gelişen sosyal ağlarla birlikte medya kavramının değiştiği bir düzen içerisinde bulunmaktadır. Dünyada internet kullanan insan sayısı yaklaşık 3 buçuk milyara yaklaşmış durumdadır. Türkiye'de internet kullanan birey sayısı 47 milyon civarındadır (Yöndar Karabeyoğlu,2018) .

\section{Dijital Pazarlamanın Sağladığı Yararlar}

Dijital pazarlamanın firma ve markalara sağladığı en büyük avantaj binlerce müşteriye çok düşük maliyetlerle aynı anda veya çok kısa zaman arlıkları ile ulaşabilme imkânı sağlamasıdır. Özellikle dijital ortamda bilhassa sosyal medya site ve uygulamalarında işletmelerin reklam ve pazarlama maliyetlerinin de düşmesi söz konusudur. Bu durumun sağladığı avantaj ile işletmeler çok daha az 
maliyetlerle daha çok fazla insana etki edebilmektedir. Dijital pazarlamayla birlikte işletmeler verdikleri hizmetler veya sattıkları ürünler üzerindeki değişiklikleri yani yeniliklerin reklamlarını hızlıca insanlara aktarabilmektedir (Yükselen, 2016) .

Müşteriler yani ihtiyaç sahipleri açısından bakıldığında ise, aynı anda birden çok markanın ürününü kıyaslayabilmekte ve fiyat performans araştırmasını hızlıca yapabilip aynı ürünü daha az fiyata verebilen firmalara ulaşabilme olanağına sahip olmaktadır. (Haşloğlu, 2006)

\section{Elektronik Pazarlama ve Dijital Pazarlama Kavramları}

Elektronik pazarlama ile dijital pazarlama kavramları birbirlerine oldukça benzemektedir. Dijital pazarlama da elektronik pazarlama da pazarlama faaliyetleri kablosuz medya, web, interaktif TV, e-mail gibi alanları kullanarak yürütülmektedir. Bu iki kavram da temelinde üç öğe barındırmaktadır. Birinci aşama olarak çeşitli kanal formlarına başvuru yapmaktır. Kablosuz uygulamalar, veri tabanı, e-mail ve web teknolojilerinde pazarlama bu kanallardandır. İkinci aşamada ise amaç; kazanç getiren müşterileri interaktif reklamlar gibi pazarlama aktiviteleriyle elde tutmaktır. Son olarak da geleneksel ve elektronik iletişim araçlarından yararlanılarak müşterilere ulaşılıp reklam ve pazarlama amacıyla yeniden yerleştirme kapsamında planlanan metotlardan faydalanmaktır (Akar ve Kayahan, 2007).

\section{Sağlık Hizmetlerinin Pazarlaması}

Sağlık hizmeti pazarlaması, hedef kitlenin ruhsal ve fiziksel sağlığı ile ilgili problemleri anlayıp, sorularını cevaplandırıp çözüm önerileri ile yararların ne şekilde sağlanabileceğini anlatarak, söz konusu kitleyi etkilemek amacıyla faaliyet gösteren pazarlama çabalarıdır (Gülmez vd., 2013).

Pazarlamanın amacı, hastalar ile hizmeti sağlayan kurumları hızlı ve en kaliteli seviyede bakımın sağlanacağı sağlık problemlerinin anlaşlarak çözüme kavuşturulacak biçimde bir araya getirmektir. Ürün, fiyat, yer ve hizmet konuları çok iyi ve dikkatli olarak planlanmalı, bunun yanında hastalar tercihleri hakkında bilgilendirilmeli ve hastaların davranışlarını etkilemek için çeşitli çabalar sarf edilmelidir (Grifftih, 1995).

Sağlık hizmetinin pazarlanmasındaki zorluk, sağlık hizmetinin çok nadir ve kişiye özel bir ürün veya hizmet olmasından kaynaklanmaktadır. Hastaların kendi hastalıkları veya Hastaneye karşı oluşan ön yargıları olabilir bu nedenle hastane sağlık hizmetlerini pazarlamak diğer alanlara kıyasla oldukça güçtür. Sağlık hizmeti pazarlamacılarının odaklanması gereken noktalar kişilerin hastalıklarından ziyade, sundukları hizmet, hizmetin kalitesi, hizmetin hızı ve tabiî ki söz konusu hizmetin hastanın yararına olması, bundan fayda sağlamasıdır. Sağlık hizmetleri işletmeleri, tüm pazarları ve dijital pazarlarında hizmeti alan kişinin uzun vadede elde etiği kazanç ve faydaları göz önünde bulundurmak zorundadır. Sağlık hizmetinin Hastanın/ tüketicinin hayatında ve sağlığında yaptığı uzun vadeli değişiklikler kişi ve hastalık sonrası hakkında bilgi sahibi olunabilmesi için tedavi sonrası hasta izlenmeli ve birkaç aylık verilerle takip edilmelidir. Dijital pazarlarda Hastane veya sağlık hizmeti alan kişilere sunulan sağlık hizmetinin faydalarının anlatılması, ilerdeki viziteler için yardımcı olmakla birlikte, ayrıca hasta ve yakınları ile ilişkileri geliştirmek için de bir temel teşkil etmektedir. Her sağlık hizmeti tüketicisi, Pazar ve hizmeti sağlayan kişi veya firmalara önemli bir getiri veren ve hayat boyu süren bir değere sahiptir (Çetin, 2018).

\section{Sağlık Sektöründe Türkiye’de Medikal Dijital Pazarlama Uygulamaları}

Sağlık hizmeti sunumunda son dönemlerde dijital pazarlama sektöründeki uygulamaların kullanılması yaygınlaşmıştır. Bu bağlamda insan sağlığının geliştirilmesine ve korunmasına yönelil bilgilendirmeler yapılmıştır. Ülkemizde özellikle son yıllarda ilaç sektörü ve hastanelerde dijital pazarlama uygulamalarının kullanımının daha halçok artmış olduğu görülmektedir (Tosyalı ve Sütçü, 2016).

Sağlık sektöründe olması istenen ve beklenen dijital pazarlama uygulamalarını ve bu uygulanmaların pazarlama yaklaşımlarını nasıl desteklediğini detaylandırmak gerekebilir. Web sitesi yapımı, Facebook ve Twitter gibi sosyal medyanın varlı̆ı̆ını yüksek düzeye taşımak, Arama Motoru Optimizasyonu (SEO), mobil uygulamalar, dijital yaklaşımların etkililiğini analiz edebilmek adına müşteri analizi ve dijital analitik bilgisi gibi uygulamalar önemli dijital pazarlama becerilerinden sayılmaktadır. Bahsi edilen bu dijital pazarlama becerileri olmadan tüm kuruluşlar rekabetçi dezavantaja sahiptir, hedefledikleri müşterileri ile hızlı iletişim kurma ve bağlanma kaynaklarını yitirirler (sosyal medya), bir web sitesi ziyareti sonucunda elde edilen bulguları bir müşteriye veya bir satın alma sürecine dönüştüremezler (müşteri dönüşümü) ve hangi dijital yaklaşımların kurumların en aktif şekilde varolduğunu göremeyebilirler (analitik). (Royle ve Laing, 2014).

Bugün ülkemizde sağlık hizmeti sunumunun hem özel sektörde hem de kamu sektörü tarafindan sunuluyor olması dijital pazarlama becerilerinin değerlendirilmesi konusunda farklı iki durumun varolmasına neden yarattığını konuşmak mümkündür. Özel sağlık hizmeti sunucusu kuruluşlarının pazarlama uygulamalarına daha çok ağırlık verdiği düşünüldüğünde; özel sağlık hizmeti sunucusu kuruluşların dijital pazarlama beceri eksiklerinin kamu sağlık hizmeti sunucusu kurumlara oranla daha az olduğunu görmek mümkün olmaktadır. Ancak bu durumun net bir şekilde ifade edilebilmesi için araştırmalara dayandırılması gerekmektedir (Çele, 2018) .

\section{Mobil Cihazlara Uygun Web Siteleri}

Google tarafından yapılmış olan çalışmaya göre, 3 hastadan en az 1 tanesi akıllı telefon veya tablet adını alan teknolojik aletleri kullanmaktadır. Randevular veya randevuların tıbbi talepleri ile ilgili her türlü aramalar mobil aygitlardan yapmaktadır. Bu sebeple, bir sağlık kuruluşunun sitesi hazırlanırken mutlaka mobil cihazlarla uyumlu özellikte olmasına dikkat edilmelidir. Bu sayede etkileşim düzeyini yükseltir ve daha fazla insan kazanımı sağlayabilirsiniz. 


\section{Arama Motoru Optimizasyonu-SEO}

Birçok alanda olduğu gibi sağlik alanında da Arama Motoru Optimizasyonu en etkili olan pazarlama tekniklerinden biridir. Potansiyel müşteriler, Arama Motoru Optimizasyonunu geliştirmek adına sağlık bakımında uzmanlığa gerek duymaktadır; bu sayede hasta web'de dolaşabilir ve onlara ulaşabilir. Eğitim içeriğiyle çokça sayıda kullanıcıya uygun ve ilgili anahtar kelimelerle ulaşılarak etkili pazarlamayı arttırarak sonuç elde etmek mümkün olabilir.(Zengin, 2017)

\section{Sağlık Sektöründe Dünya'da Medikal Dijital Pazarlama Uygulamaları}

Google'ın araştırmasına göre her 3 hastaneden en az bir tanesinin akıllı telefonlara uygun web siteleri bulunmaktadır. Hastanelerin web sitelerinde anahtar kelime arama yerleri ile hedef kitleye kolaylık sağlanır. Hastanenin pazarlanması bu şekilde arttırılır (Zenfin \& Can, 2017). Hastanelerin web sitelerinin İngilizce olması, uluslararası olarak hastanenin tanınmasını sağlamaktadır. Hastanelerin geleneksel pazarda uyguladığı ağızdan ağıza pazarlaması, dijital pazarlamada sosyal medya ile sağlanmaktadır. Belli bir hizmeti talep eden insanlar bilgiyi yalnızca sosyal medyadaki yakınlarında değil hastaneyi takip eden diğer bireylerden de bilgi edinirler (ÖKSÜZ \& ALTINTAŞ, 2017).

Arkansas eyaletinde bulunan Willins-Knightop sağllk sistemi pazarlama iletişiminde dijitalleşmeye yönelmektedir. Willis-Knighton Memorial Hastanesi 1970 de billboard la rekleme başlayan hastane günümüz medyasında halkın ilgisini çeken hikayecilik, yenilikçi profiller kullanarak yeni tanıtılan tıbbi teknoloji ve yeni oluşan pazar alanında yer edinmiştir. Hastane yöneticileri dijital reklam panoları oluşturdu. Hastane, hedef kitlesiyle iletişimi dijital panolar sayesinde geleneksel pazarlamaya göre daha iyi kuruyor. Çünkü bu hastane 24 saat boyunca istediği reklamı verebiliyor, talebe göre anlık mesaj değiştiriyor, mesajlaşma için medya firmalarına daha az bağımlılık sağlamaktadır bu faktörler kuruma birçok yarar sağlıyor. Ancak bazı mali sorunlar ve halkın o anki görüşlerini bilememenin getirdiği sorunlar olabiliyor. (Elrod \& Fortenberry Jr., 2018)

Arizona da bulunan Mayo Clinic deki tıp uzmanlarını sosyal medyada aktif bir kullanıcı olarak mobil ve hastane ortamına katmışlardır. Bu durum ayrıca hekimlerin markalarını kontrol etmeye başladıklarını gösterir. Hekimler sosyal medya sitelerin de tıp uzmanları ile iletişim kurarlar ve uzmanlık- eğitim alanlarının tanımlanmasını saplarlar. Sağlık hizmeti talep edenler hekimlerin uygulamalarını takip ederler, hastanın sağlı uzmanları ile ilk iletişimi 'hasta deneğimi' hastaneye gelmeden dijital ortamda sağlanmaktadır (John T. Wald, Farris K. , \& Kotsenas, 2017).

Kaliforniya da dijital sağlık hizmetleri alanında bazı çalışmalar yapılmıştır. İlk çalışma engelli bireylere önceden var olan sistemi kullanması için yeni bir servis oluşturmaktır. Bireyler bir alana toplandı ve yeni bakıcılar alınmadan başlangıç servis programını destekleyen internet üzerinden uzaktan servis sağlandı. İkinci çalışma kronik cilt hastalığı olan bireylere alternatif bir hizmet olarak Case A bir cihaz rehberi verildi. Bireyler bu sayede evde kendileri ile ilgilenerek telesağlık uygulamasını kullana bilmektedirler. (Muhos, Saarela, Foit Jr, \& Rasochova, 2018)

İspanyadaki hastanelerin özel hastane ve kamu hastanelerindeki internet kullanımına bakıldığında burada da özel hastanelerdeki internet kullanımı fazladır. Hastanelerin sosyal medyadaki varlığı diğer ülkelere göre düşük olsa bile sosyal medyadaki etkililiği hızla artmaktadır. Hastanelerde sosyal medya ile ilgili eğitim görülerek etkililikleri arttırılmaya çalışılmaktadır. Facebook ve YouTube da bulunan hastalar sayesinde hastaneler, hizmet kalitesini kontrol edebiliyorlar (Llatas, Millana, Bilbao, Salcedo, \& Salcedo, 2017).

ABD' de yetişkin ve çocuk hastaneleri sosyal medya kullanımına bakıldığında sosyal medyayı aktıf olarak kullananların ABD News'de daha önlerde olduğu görülmektedir. Ayrıca sosyal medyayı iyi kullanan hastaneler daha itibar sahibi hastaneler olarak kabul edilmektedir. Dünyadaki en iyi hastaneler sıralamasına sosyal medyayı en iyi kullanan hastaneler girmektedir. (Triemstra, Poeppelman, \& Aror, 2018)

Amerika'da HealthOntheNetFoundation Code gibi arama çubukları ve sosyal medya bireylerin özel bilgileri, eczanelerin bazı bilgilere ulaşması gibi sorunlar oluşturabilmektedir. ICANN gibi sağılı uygulayıcıları dijital sağlık uygulamalarını güvenilir hale getirtmek için çalışmalar yapılmıştır. Ancak yapılan nu çalışmada halk sağlığı uygulamalarının da dijitalleşmesi ile toplum sağlığının daha iyi olacağı vurgulanmaktadır (Mackey, Liang, Kohler, \& Attara, 2014).

Kanada da hamile kadınlar sağlık uzmanları ile yapılan görüşmelerin yetersiz olduğunu ve web den nu konu ile ilgili destek aldıklarını belirtmiştir. Kadınlar web 'in yanında Facebook da dâhil sosyal medyayı kullanıyorlar. Kadınların elde ettikleri bilgilerin tümünün güvenilir olamayacağı için sağlık kuruluşları düşük maliyetli, güvenilir bilgiler içeren dijital bir sağlı platformu oluşturdu. Kadınlar bu alanlara yönlendirilerek sağlık kuruluşlarının da pazarlaması yapıldı (Graham, Jocelyn E , ve diğerleri, s1-10).

\section{Sonuç}

Pazarlama gelişen teknolojiye ayak uydurarak dijitalleşmeye gitmiştir. Sağlık kuruluşları da değişen sektörde varlığını sürdürmek için dijitalleşme pazarlamasına ayak uydurmuştur. İnsanların sabırsız bir şekilde anında hizmet talebi, dünyada olan diğer hizmetleri görme olanakları dijital pazarlamanın hızla yükselmesini sağlamıştır. Dijital pazarlamayı kendine uydurabilen kurumlar, kurumun insanlar arasında tanınmasını, prestij sağlamasını, kalitesini arttırması ve maliyetleri düşürmesi gibi bir çok imkan sağlamaktadır. Son yıllarda meydana gelen çeşitli değişmeler sayesinde (teknolojinin ilerlemesi, maliyetlerde azalmaların olması ve tüketicinin bilinç seviyesi artması gibi) gelişmiş̧lik düzeyi artmasıyla vizyon ve misyonlarımız da değişiklikler meydana gelmiştir. Bu gelişmeler sayesinde iletişimin etkin olmasıyla internet gibi iletişim ağlarının kullanılması hem sağlık sektöründe hem de diğer sektörler açısından gelişme göstererek pazarlama alanlarının daha geniş açıdan ele alınmasıyla dijital pazarlama gündeme gelmiştir. Bu pazarlama alanında devamlılığın sağlayıp rekabeti artırmak için doğru, hızlı, ikna edici, etkileyici gibi özellikleri ele almaktadır. Sağlık sektörünün diğer sektörlerden farklı ve hayati öneme sahip olduğu için pazarlama olanakları da farklılık göstermektedir. Dijital pazarlamayla birlikte 
sağlık alanında hastaların hastaneye gitmesine gerek kalmadan gerekli önlemlerin alınması ve bu sayede hem zaman hem de maliyet açısından avantaj sağlamakla birlikte kişiye özel tedavi yöntemleri uygulanacaktır

\section{Kaynakça}

Akar E. Ve Kayahan C., Elektronik Ticaret Ve Elektronik İş, Nobel Yayın Dağıtım, $\quad$ İstanbul, 2007

Bilge A. Ve Göksu N., Tüketici Davranışları, Özbaran Ofset Maatbacılık, Ankara, 2010

Çetin L., Sağllk Hizmeti Veren Kurumlarda Güncel Pazarlama Teknikleri, Yüksek Lisans Tezi, Sivas, 2018

Gülmez, M., İnternet Üzerinde Ağızdan Ağıza Pazarlama Uygulama Örnekleri, Iuyd, Cilt: 2, Sayı: 1, 2011

Gülmez Mustafa Ve Dörtyol İbrahim Taylan, "The Paths From Service Quality Dimensions To Customer Loyalty: An Application On Supermarket Customers", Management Research Review, 2013

Grifftıh E., "The Well-Management Healthcare Organization", Aupha Press, Chicago 1995

Haşıloğlu B., Elektronik Posta İle Pazarlama, Beta Yayınc1lık, İstanbul, 2006

Moon M. Ve Millison D., Ateşten Markalar (Çev. T. Kalkay), Kapital Medya A.Ş. İstanbul, 2003

Royle J. Ve Laing A., The Digital Marketing Skills Gap: Developing A Digital Marketer Model For The Communication Industries, International Journal Of Information Management, 2014

Tosyalı H. Ve Sütçü C.S., Şağlık İletişiminde Sosyal Medya Kullanımının Bireyler Üzerindeki Etkileri, Maltepe Üniversitesi İletişim Fakültesi Dergisi, 2016

Yöndar Karabeyoğlu D., Türkiye'de Dijital Pazarlamada Marka Ve Tüketici İlişkisinin İncelenmesi, Yüksek Lisans Tezi, 2018,

Yükselen C., Pazarlama İlkeler-Yönetim Örnek Olaylar, Detay Yayıncılık, Ankara, 2016

Zengin S., Türkiyedeki Özel Hastanelerin Dijital Pazarlama Faaliyetleri Ve İnternet Sitelerinin Pazarlama Amaçlı Kullanım Analizi, Yüksek Lisans Tezi, İstanbul,2017

Graham, J., Moore, J., Bell, R., \& Miller, T. (2019). Digital Marketing To Promote Healthy Weight Gain Among Pregnant Women İn Alberta: An Implementation Study. 1-10.

Alabay, Y. M. (2010). Gelineksel Pazarlamadan Yi Pazarlama Yaklaşımlarına Geçiş Süreci. Dergipark, 2013-235.

Çabuk, P. D., \& Yrd.Doç.Dr. Mehmet İ. Yağcı. (2003, Eylül). Pazarlamanın Tanımı Ve Gelişimi. Pazarlamaya Çağdaş Yaklaşım (S. 2). İçinde Ankara: Nobel.

Çinibulak, M. (2018). Hastane Yöneticilerinin Sağlık Hizmetleri Pazarlamasında Dijital Pazarlama Yaklaşımının Kullanımına Yönelik Görüşlerinin Değerlendirilmesi. Hastane Yöneticilerinin Sağllk Hizmetleri Pazarlamasında Dijital Pazarlama Yaklaşımının Kullanımına Yönelik Görüşlerinin Değerlendirilmesi, 21-29. Ankara: Türkiye Sağlık Bilimleri Ve Araştırmaları Dergisi.

Elrod, J. K., \& Fortenberry Jr., J. (2018). Healthcare Establishments As Owneroperators Of Digital Billboards: Making The Most Of Excellent Roadside Visibility And High Traffic Counts To Better Connect With Patients. 30-48.

G, R., M, S., Cm, G., M, H., Ia, B., \& Vl, P. (2017). The Adaptation Of Health Care Marketing To The Digital Era. 44-46.

John T. Wald, J., Farris K. , T., \& Kotsenas, A. (2017). Managing Physicians' Medical Brand. 92, 685-686.

Llatas, C. F., Millana, A. M., Bilbao, I. B., Salcedo, M. T., \& Salcedo, V. T. (2017). Evaluating The Social Media Performance Of Hospitals İn Spain: A Longitudinal And Comparative Study. 1-11.

Mackey, T. K., Liang, B., Kohler, J., \& Attara, A. (2014). Health Domains For Sale: The Need For Global Health Internet Governance. $1-11$.

Muhos, M., Saarela, M., Foit Jr, D., \& Rasochova, L. (2018). Management Priorities Of Digital Health Service Start-Ups İn California. 43-62.

Öksüz, D. D., \& Altıntaş, D. (2017). Sağlık Turizmi Ve Dijital İletişim. Sağlık Turizminde Dijital İletişim Kanallarının Kullanımı, 5975. Journal Of Travel And Hospitality Management.

Özdaş, N., \& Canan, P. D. (2017). Dijital Pazarın Yararları. Dijital Pazarlamada Marka Yönetiminin Önemi Ve Hızlı Tüketim Sektörüne Yönelik Bir Uygulama. İstanbul: Üsküdar Üniversitesi Sosyal Bilimler Enstitüsü.

Triemstra, J., Poeppelman, R. S., \& Aror, V. (2018). Correlations Between Hospitals' Social Media Presence And Reputation Score And Ranking: Cross-Sectional Analysis. (11).

Yeşil, G., \& Özgül, P. (2018). Dijital Pazarlamanın Gelişimi. Dijital Pazarlama Faaliyetlerinin Verimliliğinin Karşılaştırllmalı Analiz. İzmir: Dokuz Eylül Üniversitesi Sosyal Bilimler Enstitüsü .

Zengin, S., \& Can, P. (2017). Hastanede Dijital Pazarlama. Türkiyedeki Özel Hastanelerin Dijital Pazarlama Faaliyetleri Ve Internet Sitelerinin Pazarlama Amaçlı Kullanım Analizi, 30-31. İstanbul: Bahçeşehir Üniversitesi. 